\title{
Medicinal plants used by Tibetans in Shangri-la, Yunnan, China Yanchun Liu ${ }^{1,2}$, Zhiling Dao ${ }^{1}$, Chunyan Yang1,2, Yitao Liu ${ }^{1}$ and Chunlin Long*1,3
}

Address: ${ }^{1}$ Kunming Institute of Botany, Chinese Academy of Sciences, Kunming 650204, PR China, ${ }^{2}$ Graduate School, Chinese Academy of Sciences, Beijing 100039, PR China and ${ }^{3}$ College of Life and Environment Sciences, China University for Nationalities, Beijing 100081, PR China

Email: Yanchun Liu - liuyanchun@mail.kib.ac.cn; Zhiling Dao - daozhl@mail.kib.ac.cn; Chunyan Yang - yangchunyan@mail.kib.ac.cn; Yitao Liu - liu@mail.kib.ac.cn; Chunlin Long* - chunlinlong@hotmail.com

* Corresponding author

Published: 5 May 2009

Journal of Ethnobiology and Ethnomedicine 2009, 5:15 doi:10.1186/1746-4269-5-15
Received: 20 January 2009

Accepted: 5 May 2009

This article is available from: http://www.ethnobiomed.com/content/5/1/15

(C) 2009 Liu et al; licensee BioMed Central Ltd.

This is an Open Access article distributed under the terms of the Creative Commons Attribution License (http://creativecommons.org/licenses/by/2.0), which permits unrestricted use, distribution, and reproduction in any medium, provided the original work is properly cited.

\begin{abstract}
Background: Medicinal plants used by the local people in Xizang (Tibet) have been investigated since the 1960s. The others out of Xizang, however, have been less understood, although they may be easily and strongly influenced by the various local herbal practices, diverse environments, local religious beliefs and different prevalent types of diseases. In 2006, two ethnobotanical surveys were organized in the county of Shangri-la, Yunnan Province, SW China, to document the traditional medicinal plants used by the Tibetan people.
\end{abstract}

Methods: After literature surveying, four local townships were selected to carry out the field investigation. Three local healers were interviewed as key informants. The methods of ethnobotany, anthropology and participatory rural appraisal (PRA) were used in the field surveys. Plant taxonomic approach was adopted for voucher specimen identification.

Results: Sixty-eight medicinal plant species in 64 genera of 40 families were recorded and collected. Among them, 23 species were found to have medicinal values that have not been recorded in any existing Tibetan literatures before, and 31 species were recorded to have traditional prescriptions. Moreover, the traditional preparations of each species and some folk medicinal knowledge were recorded and analyzed. These traditional prescriptions, preparations, new medicinal plants and folk medicinal knowledge and principles were discovered and summarized by local traditional Tibetan healers through times of treatment practices, and were passed down from generation to generation.

Conclusion: As a part of the cultural diversity of Tibetan community, these traditional medicinal knowledge and experiences may provide data and information basis for the sustainable utilization and development of Tibetan medicine, and may contribute to the local economic development. However, for many reasons, they are disappearing gradually as time goes by. Our study showed that there were abundant traditional Tibetan medicinal prescriptions and using methods. It implies that more Tibetan medicinal plants and traditional knowledge can be discovered. Further research should be done to save the wealth of these traditional medicinal knowledge and experiences before they are dying out. 


\section{Background}

There are nearly 2000 ethnic groups in the world, and almost every group has its own traditional medicinal knowledge and experiences to depend on [1]. China is a multi-racial country with 56 nationalities, of which 55 in over 18 provinces are officially recognized as ethnic minorities. The various and abundant traditional ethnic medicines from each group have made up of the great Chinese medicine [2]. Tibetan medicine is one of the most important ethnic medicines with systematic theories, like the Han group's medicine or the Traditional Chinese medicine which evolved out of the matrix of Chinese civilization over a period spanning more than four thousand years and developed into an extremely rich medical system [3-6]. Traditional Tibetan medicine which appeared in the seventh century, had later taken in the traditional Chinese medicinal theory, Indian medicinal theory, ancient Arabic medicinal theory, Greek medical theory and those of other countries around, and gradually became unique and well-known to the whole medicinal world [5,7-11].

During the long-term process of development of Tibetan medicine, many medical treatises had appeared, such as the Yue Wang Yao Zhen (Tibetan title: Sman dpyad zla ba'i rgyal po) [12], Si Bu Yi Dian (English title: the Four Tantras; Tibetan title: Rgyud bzhi) [13], Si Bu Yi Dian Lan Liu Li (English title: the Blue Beryl Treatise; Tibetan title: Vaidurya Sngon Po)[14] and Jing Zhu Ben Cao (Tibetan title: Shel Gong Shel Phreng) [15] which embodied the unique features of traditional Tibetan medicinal system with a relatively complete set of theory $[5,16,17]$. Actually, Jing Zhu Ben Cao is a widespread monograph mainly about medicinal herbals which described the morphological traits, the medicinal functions, the properties, the places of origin and the usage of Tibetan medicines. Comparing with Jing Zhu Ben Cao, other literatures are more emphasized on medical knowledge $[1,5,10]$.

The Tibetan medicinal theory is based on the "Assumption of Five Elements" and the "Hypothesis of Three Aggregates". The "Assumption of Five Elements" believed that everything came from five elements of earth, water, fire, wind and space $[5,10,18]$, so did the medicines. Moreover, it claimed that different combination of origins had formed six kinds of tastes of medicines, including sweet, sour, salty, bitter, pungent and astringent. In addition, eight traits and 17 curative effects of Tibetan medicine were concluded $[5,10,18,19]$.

Recent studies on Tibetan medicine have shown that the earliest literature dates back to the eighth century AD [20]. Almost all the Tibetan inhabited areas, including Xizang (Tibet), Qinghai, Sichuan, Gansu and Yunnan provinces, have been investigated since the 1960s and the inventory of medicinal plants comprises 2600 species [8]. Furthermore, the phytochemical, pharmacological, new drug evaluation and other aspects of research on traditional Tibetan medicines have also attracted much attention and has become the hotspot in the medicinal field $[1,5,7$ 11,16-34].

However, the medicines used by the branches of Tibetan communities distributed in other provinces may be easily and strongly influenced by the various local herbal practices, diverse environments, local religious beliefs and different prevalent types of diseases $[16,34]$. Consequently, local characters may have been formed in medicinal plants choosing, compositions of prescriptions and process of preparations which may be distinct from those in Tibet. Taking the Tibetan community in Yunnan as an example, the moving of their predecessors into northwest Yunnan dates back to the seventh century AD [35], and after living with other ethnic groups (the Yi, Naxi, Pumi communities and etc.) for such a long time, the Tibetans in Yunnan gradually formed its unique derivate style of using medicine due to various factors [20]. Though systematic theory had been formulated in the literatures mentioned above and the inventory of Tibetan medicines had also been studied, unfortunately few studies have been done on the derivate traditional knowledge and experiences of Tibetan medicines.

The local traditional Tibetan medicinal knowledge and managing experiences which are practiced, accumulated and passed down from generation to generation may play a significant role in the sustainable use and development of Tibetan plants resources [36,37]. Nevertheless, along with the disappearing of biodiversity and negative effects of mainstream culture, the traditional/folk medicinal knowledge of many ethnic groups is facing the danger of losing [38-41]. Furthermore, the losing of the traditional medicinal knowledge and culture which is the same as the disappearing of biodiversity is not a reversible process [2]. Therefore, it is imperative to carry out the systematic investigation and research on the local traditional Tibetan medicinal knowledge.

Diqing Tibetan Autonomous Prefecture, Northwest Yunnan, dominated by the Tibetans, is one of the spreading areas of traditional Tibetan medicine. Because of its topographic diversity, unique location and climate condition, a great number of plants, animals and minerals are used as medicine [42]. Anderson and his group had been fascinated by the Tibetan medicines in the Mt. Kawa Karpo in Diqing Tibetan Autonomous Prefecture and a vegetation analysis was made there [34], but no effort on recording the traditional Tibetan medicinal knowledge was made. In another case, aiming at making the scientific name of the medicines clear, Prof. Yang Jingsheng had been to 
Xizang (Tibet) and Northwest Yunnan many times since 1964 to investigate the Tibetan medicines, and had written a book "Tibetan Medicines in Diqing Tibetan Autonomous Prefecture" containing more than 679 species of Tibetan medicines. Furthermore, the revision or confirmation of the medicinal uses, the language derivation of Tibetan dialect and the name of 40 species of Tibetan medicinal plants were included [2]; some known chemical compositions and pharmacological achievement of Tibetan medicines were also simply recorded [43]. However, he also did not carry out any ethnobotanical studies on the local traditional Tibetan medicinal knowledge and experiences.

For these reasons, we conducted an ethnobotanical study containing the local traditional prescriptions, prepara- tions, uses and other local characters on Tibetan medicinal plants in Shangri-la, and hoping that the local traditional medicinal knowledge and experiences would be recognized, saved and enriched, and the data and information of the study result would contribute to the sustainable use and development of Tibetan medicine through the study.

\section{Study area}

Shangri-la County (Figure 1), formerly named as Zhongdian County, located between $26^{\circ} 52^{\prime} 28^{\circ} 48^{\prime} \mathrm{N}$ and $99^{\circ} 23^{\prime} 100^{\circ} 31^{\prime} \mathrm{E}$, is one of the three counties administered by Diqing Tibetan Autonomous Prefecture, Northwest Yunnan. It is located in the south of Qinghai-Tibet Plateau and the east of Himalayas, and the junction of Yunnan, Tibet and Sichuan provinces. The world-famous

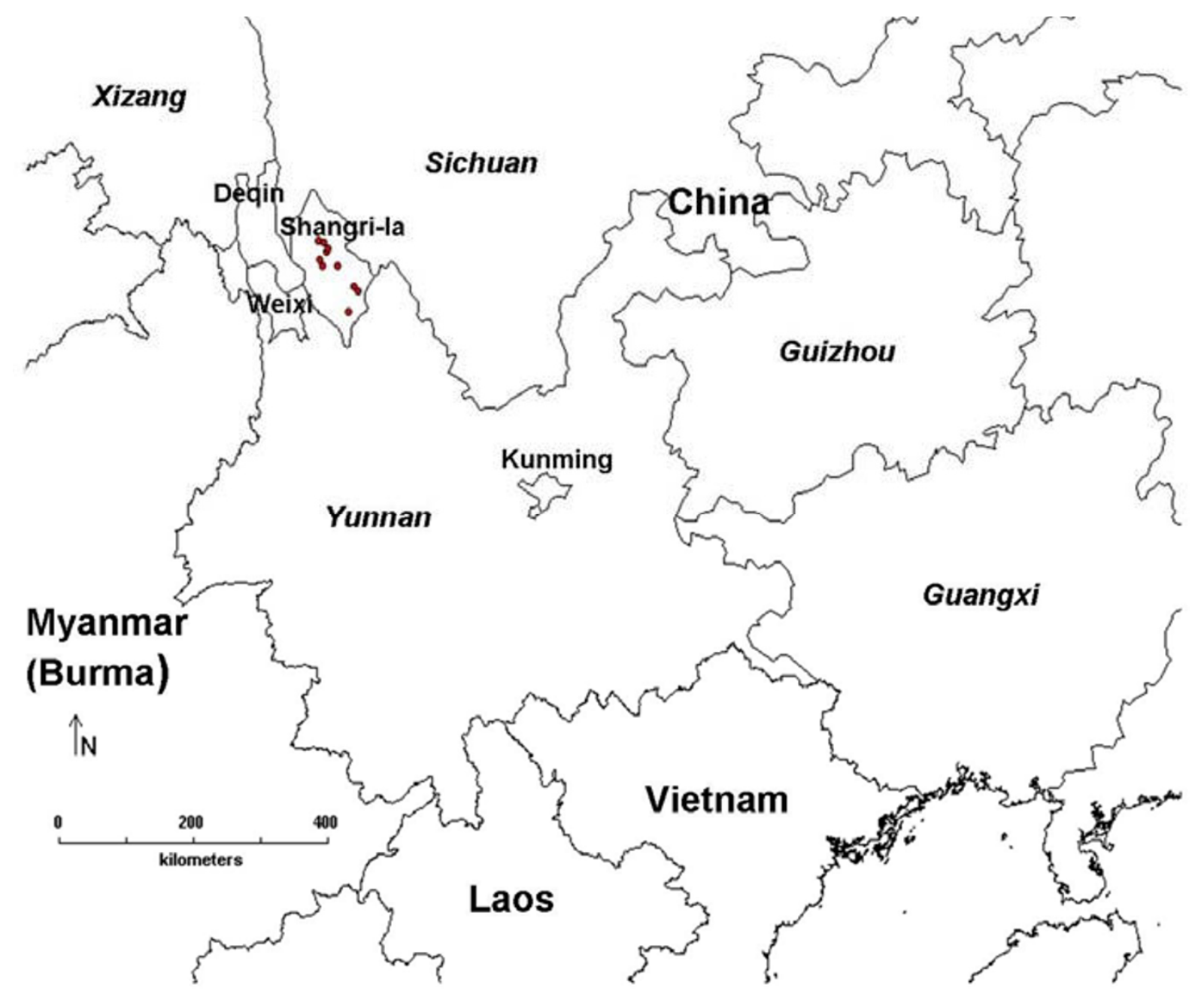

Figure I

Study area - Shangri-la County. 
area called Three Parallel Rivers (Nujiang River or Salween River, Lancang River or the Mekong River, and Jinsha River or Upper Yangtze River) covers the whole Shangri-la County whose total area accounts $11,613 \mathrm{~km}^{2}$. Shangri-la is the largest county in Yunnan Province but has a lowest population density of 10.46 people $/ \mathrm{km}^{2}$ with a population of nearly 130,000. Besides the dominant nationality of Tibetan in Shangri-la, there are also Han, Naxi, Yi, Bai communities, among which mutual cultural influence and communications have existed for a long time [44].

The terrain of Shangri-la is higher in north and lower in south. The place with the highest altitude of 5,545 m above sea level in Shangri-la is the Gezong Snow Mountain in North, and the one with the lowest altitude of $1,503 \mathrm{~m}$ is the Laohuofang Village in Luoji Township in south. Between the two altitudes, the climate zone of Shangri-la is divided into North Semi-tropical Zone, Temperate Warm Zone, Temperate zone, Temperate Cold zone, Frigid Zone and Glacier Zone. Abundant medicinal resources are distributed in Shangri-la under its unique geological location and climate condition [44].

The ethobotanical study on local traditional medicinal knowledge and experiences in Shangri-la may represent the derivate branch of Tibetan medicinal knowledge of Diqing Tibetan Autonomous Prefecture, NW Yunnan.

\section{Materials and methods}

According to the usual tools and methods used in conducting ethnobotanical study, we carried out our work in following 4 steps: literature surveying, sites selection, field study and herbarium work. Participatory Rural Appraisal (PRA) [45-50], ethnobotanical and anthropological methods was applied during the process of investigation and field study $[44,51,52]$.

\section{Literature surveying}

Relevant literature were surveyed and consulted to obtain the information on the topography of Shangri-la and information on the Tibetan medicine and traditional healers which were helpful in choosing the specific study sites $[1,29,42-44]$. The general Tibetan medical information was also obtained by reading books and literatures before field study according to the guide manual on the ethnobotanical methods $[48,51]$.

\section{Selecting sites and searching local healers}

We selected four local townships of three different altitudes at which the vegetation type distributing is different to carry out our investigation: Xiao Zhongdian Township with an altitude of 3,240 m, Nixi Township of 3,160 m, Luoji town of 2,196 m and Jinjiang Township of 1,900 m [44].
Guiding by the principles of direct learning from local people of PRA [45-49], we widely asked local Tibetans about the local healers in their villages and towns. During the searching and talking, we found that most Tibetans in Yunnan, especially the official workers, traders and local healers who have to contact with different people very often, now can speak basic mandarin. So we all speak mandarin and didn't use any interpreters in communicating.

Finally, we found Qiao Ruxiang, a local healer from Xiao Zhongdian Township, Gu Jiangzhao, a herbalist from Jinjiang Township and Wang $\mathrm{Za}$, a local healer from Nixi Township. Among them, Wang $\mathrm{Za}$ is the only one who had attended the Chinese Primary School built all over China but not the Tibetan Buddhism School used to open only for Lama in Shangri-la. They all knew some Tibetan medicinal theory which passed down from their ancestors, and they knew few about the famous Tibetan medical treatises in history.

\section{Field study}

The field study was carried out twice in July and August, 2006, in addition to several pilot investigations in the region.

Before the field study, we discussed with the local healer, asked about his opinion and made decisions together on where to go and what to do in the following few days. Our intention to enable the local healers to conduct their own analysis, and to plan and take action is accord with one of the main principles of PRA [45-50] and achieved good result in the end.

During the field study, some of us collected specimens of medicinal plants known by the healers and conversations naturally came about the medicinal plants, the related knowledge and experiences. The healers were the main talker, and we gave suitable questions and responses according to what they said. One of us was responsible for writing down all the answers and information given by the healers. The open-ended interview of anthropological technique was applied here [48].

We didn't found any local herbalist in Luoji town, but fortunately we widely collected some plants there, of which some were later recognized by Wangza from Nixi Township as medicinal plants used by Tibetans.

Under the guide of local traditional Tibetan healers, specimens of medicinal plants which are commonly used by the healers were collected, and the local Tibetan pronunciations, traditional prescriptions, preparations and medicinal usages of the plants were recorded according to the requirement of making inventory of ethnobotanical 
methods [51,52]. Concerning about the local Tibetan pronunciations, we would like to state here that they are claimed different from the formal Tibetan pronunciation in Tibet by local Tibetans. Some of the plants were even pronounced like Chinese. We didn't change the name and just wrote them down phonetically.

As the traditional Tibetan healers are so few that we could hardly find more, or in some cases, some healers were too old to guide us in the field. Therefore it seems even more urgent to collect the traditional Tibetan medicinal knowledge and experiences from folk healers before the traditional knowledge and experience dying out.

\section{Studies in herbarium (KUN)}

Plants specimens were examined and identified by experts and the authors. The specimens were registered and were under further study before being deposited in the Herbarium of the Kunming Institute of Botany, Chinese Academy of Sciences (KUN).

\section{Results and Discussions Sixty-eight Tibetan Medicinal Plants}

Through this study, 68 medicinal plant species belonging to 64 genera in 40 families were collected. All the 68 species are listed in alphabetical order in Additional file 1, Appendix S1. Twenty-three of the 68 medicinal plant species were found to have medicinal values that have not been recorded in any literatures related to medicinal plants in China and neighborhood countries before $[16,43,53-55]$, and no records of them were found in a online databases of a resource and information centre for 7300 edible and other useful plants [56] (labeled "*" in appendices attached to this paper). Moreover, the database gives a clue of a lot of useful literatures on the medicinal uses of plants [57-87] which are important for studying medicinal plants. The voucher specimen number, botanical family, local Tibetan pronunciations, plant parts/product used, the traditional preparations and uses of all the 68 plants are also recorded and reported in the present paper.

Table I: The percentage of main plant groups
The main altitude range of medicinal plants distributed in Tibet is from 3,600 5,200 m [88]. Nevertheless, due to the geological restrictions, $30.9 \%$ of the medicinal plants collected under the guide of local Tibetan healers were from 3,000 3600 m in Shangri-la, and 69.1\% were from below the altitude of 3,000 $\mathrm{m}(27.9 \%$ from $2800 \sim 3000$ $\mathrm{m}, 32.4 \%$ from $2100 \sim 2700 \mathrm{~m}$, and $8.8 \%$ from $1900 \sim 2000 \mathrm{~m}$ ). This altitude range directly influences the medicinal plants species being used.

This number of traditional Tibetan medicinal plants represents only a small fraction of the flora of Shangri-la. Among the 40 families, Asteraceae is the one with the most medicinal plants in our study (seven species), followed Labiatae and Umbelliferae (5 species each). Fiftyseven $(83.8 \%)$ of the medicinal species are Dicotyledons, seven are Monocotyledons (10.3\%), two are ferns $(2.9 \%)$, one is fungus $(1.5 \%)$ and one is gymnosperm $(1.5 \%)$. The percentages of the plant groups in this study are close to that in "Tibetan Medicine in Diqing Tibetan Autonomous Prefecture" with $86.6 \%$ of Dicotyledons, $8.3 \%$ of Monocotyledons, $1.2 \%$ of fungi, $2.9 \%$ of ferns and $0.3 \%$ of gymnosperm (Table 1).

\section{Thirty-one medicinal plants with $\mathbf{3 3}$ prescriptions}

Among the 68 medicinal plant species, 31 have been written down with 33 traditional prescriptions. Most ingredients of the prescriptions are plants, of which the local name and the botanical Latin name were written down; some ingredients are things like liquid wax, tallow and muskiness. All the plants have been listed in alphabetical order with the prescriptions (Additional file 1, Appendix S2).

Though there are only 33 local traditional prescriptions of 31 plants, these prescriptions are recorded neither in "Tibetan Medicine in Diqing Tibetan Autonomous Prefecture" [42] nor in the famous ancient Tibetan medicinal monograph of "Jing Zhu Ben Cao" mentioned above [15]. The prescriptions' compositions of one species are relatively simpler than that of the species of the same genus in Tibet which are both easily attainable in Shangri-la and

The Percentage of Species from the Medicinal The Percentage of species in "Tibetan medicine in Diqing Plants in our Study (\%) Tibetan Autonomous Prefecture" (\%)

Fungi
Lichens
Algae
Pteridophyta
Gymnospermae
Dicotyledoneae
Monocotyledoneae
Total

1.5

0

0

2.9

1.5

83.8

10.3

100
1.2

0.6

0.1

2.9

0.3

86.6

8.3

100 
Tibet respectively [89]. Few prescriptions are even derivate from other ethnic groups in Yunnan, such as that of the "Phytolacca acinosa Roxb." which was learned to from Yi community [90].

\section{Inventory of plant parts/product used}

The plant parts/product used for medicinal purposes are shown in the table (Table 2), and the roots (27\%) may be concluded as the most frequently used part, and the leaves $(16 \%)$ follows the second. However, the stem $(6 \%)$ is the second frequently used one if we count the rhizome $(11 \%)$, tuber $(6 \%)$ and bulb $(1 \%)$ in, i.e. $23 \%$ in total. Local traditional healers consider all the underground part as roots, including the rhizome, tuber, bulb and underground sclerotium. In this philosophy, the underground part which accounts $47 \%$ was more frequently used than the overground one in local Tibetan medicine.

The classic concepts on the plant part used claim that the overground part and whole plant accounts a large percent of $70 \%$ [84] in traditional Tibetan medicine which are more than that $(53 \%)$ of this study. We ascribe the reasons to the environment the local healers dwelled in and the medicinal plants the healers usually collected.

Types of preparations and main diseases

According to the "Jing Zhu Ben Cao" (Tibetan title: Shel Gong Shel Phreng) and other modern literatures

Table 2: Plant parts/product used

\begin{tabular}{lrr}
\hline Plant Part/Product & Number of uses & \\
\hline & & $\%$ \\
Roots & 22 & 27 \\
Leaves & 13 & 16 \\
whole plant & $1 \mathrm{I}$ & 14 \\
Rhizome & 9 & 11 \\
Tuber & 5 & 6 \\
Stem & 5 & 6 \\
Fruits & 4 & 5 \\
Seeds & 3 & 4 \\
Bark & 3 & 4 \\
Bulb & $\mathrm{I}$ & $\mathrm{I}$ \\
Twig & $\mathrm{I}$ & $\mathrm{I}$ \\
Turpentine & $\mathrm{I}$ & $\mathrm{I}$ \\
underground sclerotium & $\mathrm{I}$ & $\mathrm{I}$ \\
Fruits & $\mathrm{I}$ & $\mathrm{I}$ \\
Flowers & $\mathrm{I}$ & $\mathrm{I}$ \\
\hline Total & & \\
\hline & $8 \mathrm{I}$ & 100 \\
\hline Underground & & $\%$ \\
Overground & & \\
whole plant & 38 & 47 \\
\hline Total & 32 & 39 \\
\hline
\end{tabular}

$[15,88,91]$, there are six types of preparations: powders, pills, adhesive plasters, decoctions, medicinal wines and medicinal butters. Similar to the traditional preparations documented in "Jing Zhu Ben Cao", decoction (63\%) and powder (18\%) are commonly used, but medicated wine $(4 \%)$ is not so often used (Table 3$)$. However, distinct from the traditional preparation types, plants being stewed with meat or steamed with egg which is thought to be easily assimilated and have favorite tastes are also recommended by local healers.

The 68 traditional Tibetan medicinal plants may cure 37 kinds of diseases, among which the dysentery is the most common illness treated (Table 4). Comparing with the 10 common efficacies of traditional medicines in Tibet (cure cold/relieving a fever, clearing away heat from visceral organs, curing tracheitis, controlling tuberculosis, relieving rheumatism, antalgic uses, reducing the blood pressure, curing fractures and gynaecological diseases) [88], only four diseases among the first ten prevalent ones in this study are as the same (cold/fever, fractures, rheumatism and gynaecological diseases), which implies the prevalent diseases in Shangri-la are different from those in Tibet.

\section{Four tastes of medicines}

Interesting principles are expressed by one (Wang Za from Nixi township) of the three traditional Tibetan healers in Shangri-la. Different from the six tastes of Tibetan medicine in "Jing Zhu Ben Cao", four tastes are concluded by them including bitter, pungent, sour and fishy. Furthermore, plants with a bitter taste are thought to be helpful in controlling inflammation and relieving pain; pungent plants may contribute to control inflammation and cure a cold; sour ones are considered to be useful in warming the internal organs, especially the stomach; plants with a fishy tastes may relive a cough and clear away heat in lung.

\section{Choosing medicines by altitude}

Moreover, instead of plants from higher altitude, the same plant species colleted in place with lower altitude are only taken as medicine by person from higher altitude, and people inhabited in place with higher altitude would like to take medicinal plants from lower altitude. The local Tibetan healers explained that the plants from different altitude may contain some substances which may be lacked of in the plants from the same altitude, and taking the plants from different altitude as medicine would be more helpful in curing diseases.

These principles and knowledge are explained by authors to be close related to the living environment of Tibetan in Shangri-la. The terrain of Shangri-la is higher in north and lower in south and Tibetan are distribute both in south and north, so did medicinal plants. For example, the 
Table 3: Preparation methods

\begin{tabular}{|c|c|c|}
\hline Kind of Preparation & Number of Species with Different Preparation & Occupied Percentages (\%) \\
\hline Decoction & 43 & 63 \\
\hline Powder & 12 & 18 \\
\hline Crushing fresh plant & 4 & 6 \\
\hline Stewing with meat & 3 & 4 \\
\hline Medicinal wine & 3 & 4 \\
\hline Steaming with egg & 2 & 3 \\
\hline Turpentine & I & I \\
\hline Total & 68 & 100 \\
\hline
\end{tabular}

plants of Saussurea sp. are actually have better curative effects if being collected above an altitude of 3,000 m and snow line; and "Phytolacca acinosa Roxb." grows better in place of lower altitude and will be more helpful when being used as medicine.

\section{Conclusion}

The main altitude range of the study sites in Shangri-la are between 1,900 3,600 which directly influences the medicinal plant used there. Including the local prescriptions' compositions, the dominant plant part being used, the types of preparations, the common diseases cured, the local four tastes of medicine and choosing medicines by altitude, all the traditional medicinal knowledge and principles are distinct with local characters from that in Tibet. This traditional knowledge which was accumulated by local healers through making use of the special plant resources in Shangri-la and learning from treatment practices and others' experiences has its own character and local style due to the important impacts from local geological environments, climate and cultural conditions, herbal practices and different prevalent types of afflictions in Shangri-la.

Furthermore, the traditional medicinal knowledge with local characters which was summarized by local traditional healers was accumulated and passed down from generation to generation. The investigation and documentation of these local traditional principles, experiences and knowledge will not only be an inheritance and spreading of traditional Tibetan medicinal knowledge but also be a supplement and conservation of the wealth of Tibetan cultural diversity and culture legacy. And these traditional medicinal knowledge and experiences may also play a significant role in conserving local biodiversity and contribute to the local economic development [92].

Moreover, the 23 plant species which are newly showed to have medicinal values imply that there are much more local Tibetan medicinal plants and traditional knowledge waiting to be discovered and recorded. Both medicinal plant species newly discovered and the folk medicinal knowledge and culture recorded will provide basic data and information to the sustainable utilization and development of Tibetan medicine, to the new drug development and to the further research of traditional patent medicines [89,93].

However, during the period of investigating, most traditional Tibetan healers were found to be almost 70 years old, and their descendants are scarcely willing to inherit this traditional profession and the precious traditional knowledge handed down They prefer other jobs with more income instead. They believe that the traditional medicines are not so indispensable to their life nowadays and their reasons are given as follows: 1) the medical treatment of Han community is more advanced and has better condition than the traditional ones; 2) Tibetan became more and more dependent on the money-consuming substances outside their village, but traditional healers didn't earn much.

It can be concluded that because of the long-term influence from Han community's culture and way of life, traditional Tibetan medicinal culture are facing the danger of dying out which would be a great loss not only to the Tibetan cultural wealth but also to the great culture diversity of China. It is urgent that we should carry out further study on the traditional medicinal knowledge and experiences handed down in the folk to prevent its disappearing and make the best of it.

It is possible to give appropriate suggestions on how to promote the sustainable utilization of Tibetan medicinal resources and the local economic development only when the Tibetan medicinal resources had been fully investigated and the further ethnobotanical study on local traditional Tibetan medicinal knowledge and experiences had been done.

\section{Competing interests}

The authors declare that they have no competing interests. 
Table 4: Diseases/symptoms cured by of the 68 plants

\begin{tabular}{|c|c|c|}
\hline & Number of diseases & \\
\hline & & $\%$ \\
\hline Dysentery & II & 8.73 \\
\hline Gastropathy & 10 & 7.94 \\
\hline Cold, fever & 10 & 7.94 \\
\hline Rheumatism arthritis & 9 & 7.14 \\
\hline Fractures & 7 & 5.56 \\
\hline Cough & 6 & 4.76 \\
\hline Sciatica & 6 & 4.76 \\
\hline Wounds & 6 & 4.76 \\
\hline Toxic condition & 6 & 4.76 \\
\hline Gynaecological diseases & 6 & 4.76 \\
\hline Promoting circulation of blood & 4 & 3.17 \\
\hline Diuresis & 4 & 3.17 \\
\hline Feebleness & 4 & 3.17 \\
\hline Sterility & 3 & 2.38 \\
\hline Toothache & 3 & 2.38 \\
\hline Tracheitis & 2 & 1.59 \\
\hline Internal hemorrhage & 2 & 1.59 \\
\hline External hemorrhage & 2 & 1.59 \\
\hline Inflammation & 2 & 1.59 \\
\hline Hepatitis & 2 & 1.59 \\
\hline Dyspepsia & 2 & 1.59 \\
\hline Neuralgia & 2 & 1.59 \\
\hline Enteritis & 2 & 1.59 \\
\hline Contusions & 2 & 1.59 \\
\hline Hemoptysis & I & 0.79 \\
\hline Pneumonia & I & 0.79 \\
\hline Measles & I & 0.79 \\
\hline Hemorrhoids & I & 0.79 \\
\hline Ophthalmic disease & I & 0.79 \\
\hline Cardialgia, & I & 0.79 \\
\hline Food poisoning & I & 0.79 \\
\hline Ascites, hydropsy & I & 0.79 \\
\hline Cystitis & I & 0.79 \\
\hline Anthelmintic & I & 0.79 \\
\hline Calvities & I & 0.79 \\
\hline Chilblain & I & 0.79 \\
\hline Antenatal pain & I & 0.79 \\
\hline Total & 126 & 100 \\
\hline
\end{tabular}

\section{Authors' contributions}

Author YCL performed the interviews with the healers, identified the herbarium specimens with CYY, drafted and finalized the manuscript with CLL. Author ZLD joined YCL to perform interviews. Author CYY joined YCL to perform interviews, identified herbarium specimens with YCL. Author YTL joined YCL to perform interviews. Author CLL supervised the research works and finalized the manuscript with YCL.

\section{Additional material}

\author{
Additional file 1 \\ Appendices. Appendix 1 Medicinal plants used by the Tibetans in \\ Shangri-la and Appendix 2 Thirty-three traditional prescriptions of 31 \\ medicinal plant species. \\ Click here for file \\ [http://www.biomedcentral.com/content/supplementary/1746- \\ 4269-5-15-S1.pdf]
}

\section{Acknowledgements}

The field study was partly supported by the Ministry of Education of China (B08044 and MUC-985-3-3). We are grateful to all the faculty members of the Research Group for Biodiversity and Plant Resources and the Herbarium (KUN) for the helping during the identifying work of specimens, and especially thank the people who shared their knowledge and information before and during the whole period of investigation. We would like to express our sincere gratitude especially to Qiao Ruxiang, Gu Jiangzhao, Wang Za for sharing their traditional medicinal knowledge and their immense help and cooperation during the field work in the Tibetan villages of the four townships. We are grateful to Selena Ahmed, an American PhD candidate in ethnobotany at the New York Botanical Garden for her editing the English.

\section{References}

I. Yang JS: Tibetan medicine. In Ethnobotany and Sustainable Utilization of Plant Resources Edited by: Xu JC. Kunming: Science and Technology Press of Yunnan; 2000:65-75.

2. Huai HY, Pei SJ: Medicinal ethnobotany and its advances. Chinese Bulletin of Botany 2002, 2(19): I29-136.

3. Cai JF, Zhen Y: Medicine in Ancient China. In Medicine Across Cultures: History and Practice of Medicine in Non-Western Cultures Edited by: Selin H. Kluwer Academic Publishers; 2003:49-73.

4. Zhu YP, Woerdenbad HJ: Traditional Chinese herbal medicine. Pharmacy World \& Science 2005, 4(I7): I03-III.

5. Meyer F: Theory and Practice of Tibetan Medicine. In Oriental Medicine: An Illustrated Guide to the Asian Arts of Healing Edited by: Alphen JV, Aris A. Chicago. Serindia Publications; 1995: 109-143.

6. Vercammen D: Theory and Practice of Chinese Medicine. In Oriental Medicine: An Illustrated Guide to the Asian Arts of Healing Edited by: Alphen JV, Aris A. Chicago: Serindia Publications; 1995:157-196.

7. Bechwith $\mathrm{Cl}$ : The introduction of Greek medicine into Tibet in the seventh and eighth centuries. Journal of the American Oriental Society 1979, 99:297-3।3.

8. Shang YH, Liu C, Peng LX: The status and prospects of research on Tibetan medicine. Journal of Southwest University for Nationalities 2006, I(32): | 140-I 44 .

9. Clifford T: Tibetan Buddhist Medicine and Psychiatry-The Diamond Healing. New Delhi: Motilal Banarsidass; 1990:47-64.

10. William R, Steiner P: Cultural Perspectives on Traditional Tibetan Medicine. In Medicine Across Cultures: History and Practice of Medicine in Non-Western Cultures Edited by: Selin H. Kluwer Academic Publishers; 2003:85-II 3.

II. Tokar E: Transformation and Balance: The Principles of Tibetan Medicine in the Context of American Healthcare. Unified Energetics 2006, 2:47-5I.

12. Tibetan Medical \& Astrological Institute: Sman dpyad zla ba'i rgyal po. Dharamsala, India (reprint); 1994.

13. Tibetan Medical \& Astrological Institute: Rgyud bzhi. Dharamsala, India (reprint); 1994.

14. Desi Sangye Gyatso: Vaidurya Sngon Po. Shanghai: Shanghai Science and Technology Press (reprint); 1987.

15. Tibetan Medical \& Astrological Institute: Shel Gong Shel Phreng. Dharamsala, India (reprint) 1994.

16. Salick J, Byg A, Amend A, Gunn B, Law W, Schmidt H: Tibetan Medicine Plurality. Economic Botany 2006, 60(3):227-253. 
17. Li LY, Zhan D, Wei YF: Conservation of endangered species resources of Tibetan medicine in China. Journal of Chinese Materia Medica 2002, 8(27):56I-564.

18. Duo J: A summary of "Assumption of Five Elements" of Tibetan medicine. Journal of Medicine \& Pharmacy of Chinese Minorities 1998, I(4):3-4.

19. Ding YF, Li F, Yang H: A Brief exposition on study of different nationalities' traditional drugs of China. Journal of Medicine \& Pharmacy of Chinese Minorities 2001, 7(I):20-22.

20. Yang JS: A review on the derivation of Xizang(Tibetan) drugs and the advance of its research. Acta Bot. Yunnanic, China 1988.

21. Tsarong TJ: Tibetan Medicinal Plants Kalimpong: Tibetan Medical Publications; 1994

22. Chen $X L$, Zhang J: Recent observation of curative effect of the Yang-Zong-San-Bao liquid. Chinese Ethnomedicine and Ethnopharmacy 1995, 10(5): 18-20.

23. Guo PJ: The suggestion of development strategy of Tibetan medicine of Qinghai. Science and Technology of Qinghai 2002, 9(2):20-22.

24. La MJ, Yang L: A brief introduction on the process of preparations of Tibetan medicine. Journal of Medicine \& Pharmacy of Chinese Minorities 2002, 8(13):26

25. Leng BJ, La MC: Elementary view of the research and development of the Tibetan medicine of China. Journal of Medicine \& Pharmacy of Chinese Minorities 1998, 4(I):43-44.

26. $\mathrm{Li}$ MX, Jia ZP, Shen T: Determination of total iridoid glycoside in Lamiophlomis rotata (Benth.) Kudo and its preparation by spectrophotometry. Traditional Chinese Drug Research \& Clinical Pharmacology 2006, I(I 7):45-47.

27. Liu DH, Chen LP, Bian BDZ: The characteristics of using Tibetan medicine. Chinese Journal of Ethnomedicine and Ethnopharmacy 2002, I7(5):226-228.

28. Qi Zheng Industry Ltd. of Gansu: The clinic observation of $\mathbf{I} 50$ examples of curing contusion and sprain with Tibetan medicine "Qi Zheng Analgetic Stick". Journal of Medicine \& Pharmacy of Chinese Minorities 1996, 2(4): 16-17.

29. Wang D: Elementary view of the development and prospect of Tibetan medicine. Journal of Medicine \& Pharmacy of Chinese Minorities 200I, 7(2):3-5.

30. Wu HF, Geng PL: The present situation and prospect of the development of the research on Tibetan medicine. Journal of Chinese Medicinal Materials 2002, 25(I):65-66.

31. Yang LJ, Yang XD, Li L: Studies on the chemical constituents of Lagotis yunanensis W. W. Smith. Journal of Chinese Medicinal Materials 2006, 29(2): I28-130.

32. Yang YS, Ma XM, Zhang YP: The bacteriostat activity study of the main chemical composition of Tibetan medicine: Chrysosplenium nudicaule Bunge. Chinese Traditional Patent Medicine 2006, 28(2):298-299.

33. Zeng $Y$, Chen $X \mid$ : Advances in studies on traditional herb Lamiophlomis rotata (Benth.) Kudo. Chinese Traditional and Herbal Drugs 200I, 32( I 2): I I4I-I I43.

34. Anderson DM, Salick J, Moseley RK, Ou XK: Conserving the sacred medicine mountains: a vegetation analysis of Tibetan sacred sites in Northwest Yunnan. Biodiversity and Conservation 2005, | 4:3065-309|.

35. Guo J, Duan YM, Yang FQ: A General Review of the Minorities in Yunnan. Kunming: Yunnan People's Press; 1999:560-564.

36. Pei SJ: Ethnobotany and the development of plant resources. Acta Botanica Yunnanica 1988:135-144.

37. Rao RR: Traditional knowledge and sustainable development: key role of ethnobiologist. Ethnobotany 1996, 8: |4-24.

38. Cox PA: Saving the ethnopharmacological heritage of Samoa. Journal of Ethnopharmacology 1993, 38:181-188.

39. Huai HY, Pei SJ, Xu JC: Indigenous knowledge on 'Banlangen' (Baphicacanthus cusia: Acanthaceae) of the Hani people. Ethnobotany 1998, 10:127-129.

40. Huai HY, Xu JC: Indigenous knowledge: inexhaustible information 'back' to toxin research. Toxicon 2000, 38:745-746.

4I. Pei SJ: Ethnobotanical Approaches of Traditional Medicine Studies: Some Experiences From Asia. Pharmaceutical Biology 200I, 39:74-79.

42. Zhang S: The ecological environment and the distribution of the Tibetan medicinal materials in Diqing Tibetan Autonomous Prefecture, Yunnan. Chinese Journal of Ethnomedicine and Ethnopharmacy 2000, 47:35I-352.
43. Yang JS: Tibetan Medicine in Diqing Tibetan Autonomous Prefecture. Kunming: Yunnan Nationality Press; 1987.

44. The Compilation Committee of the Records of Diqing Tibentan Autonomous Prefecture: The Records of Diqing Tibetan Autonomous Prefecture. Kunming: The Nationality Press of Yunnan; 2003:74.

45. Theis J, Grady HM: Participatory Rural Appraisal for Community Development. London: International Institute for Environment and Development; I99I.

46. World Resources Institute: Participatory rural appraisal handbook. Natural Resources Management Support Series No.I, Washington DC: World Resources Institute; 1991.

47. Long CL, Wang JR: The Principle, Method and Application of Participatory Rural Assessment. Kunming: Yunnan Science and Technology Press; 1996.

48. Martin GJ: Ethnobotany - A methods Manual London: Earthsacn; 2007.

49. Chambers R: Participatory Rural Appraisal (PRA): Challenges, Potentials and Paradigm. World Development 1994 I0(22): I437-I454.

50. Chambers R: The Origins and Practice of Participatory Rural Appraisal. World Development 1994, 7(22):953-969.

51. Alexiades M, Sheldon J: Selected guideline for ethnobotanical research: a field manual New York: The New York Botancial Garden; 1996.

52. Ford RI, (Ed): The Nature and Status of Ethnobotany Anthropological Papers: No. 67. Ann Arbor: Museum of Anthropology, University of Michigan; 1978.

53. Zhao ZZ, Xiao PG: Encyclopedia on Contemporary Medicinal Plants Volume 1-3. Shanghai: Shanghai World Publishing Corporation; 2008.

54. Subrat N: Ayurvedic Industry: Sustainable Management of Medicinal Plants. In Himalayan Medicinal and Aromatic Plants, Balancing Use and Conservation Edited by: Thomas Y, Karki M, Gurung K, Parajuli D. WWF Nepal Program, IDRC and PPI; 2005:79-108.

55. Ghimire SK, Thomas $Y$ : Approach to in situ conservation of threatened Himalayan Medicinal Plants: A case study from Shey-Phoksundo National Park, Dolpo. In Himalayan Medicinal and Aromatic Plants, Balancing Use and Conservation Edited by: Thomas Y, Karki M, Gurung K, Parajuli D. Kathmandu: the Printhouse; 2005:209-234

56. Plants For A Future: Plant Database Search Page. [http:// www.pfaf.org/database/index.php]

57. Chittendon F: RHS Dictionary of Plants plus Supplement Oxford: Oxford University Press; 1956

58. Grieve M: A Modern Herbal. Penguin 1984.

59. Chiej R: Encyclopaedia of Medicinal Plants Edinburgh: MacDonald; 1984.

60. Launert E: Edible and Medicinal Plants London: Hamlyn; |98I.

61. Triska J: Hamlyn Encyclopaedia of Plants London: Hamlyn; 1975

62. Lust J: The Herb Book New York: Bantam books; 1983

63. Uphof JC: Dictionary of Economic Plants Weinheim: H.R. Engelmann; 1959.

64. Polunin O, Stainton A: Flowers of the Himalayas Oxford: Oxford University Press; 1984

65. Schery RW: Plants for Man Prentice Hall; 1972.

66. Usher G: A Dictionary of Plants Used by Man London: Constable; 1974.

67. Howes FN: Vegetable Gums and Resins Waltham: Chronica Botanica; 1949.

68. Frohne D, Pfander HJ: A Colour Atlas of Poisonous Plants England: Wolfe Publishing Ltd; 1983.

69. Zhang JW: The Alpine Plants of China New York: Gordon \& Breach, Science Publishers; 1982.

70. The Academy of Traditional Chinese Medicine in Hunan Province, China: A Barefoot Doctor's Manual Philadelphia: Running Press; 2003.

7I. Mills SY: The Dictionary of Modern Herbalism: A Comprehensive Guide to Practical Herbal Therapy New York: MJF Books; 1997.

72. Kariyone T: Atlas of Medicinal Plants Osaka: Takeda Chemical Industries; 197I.

73. Yang HC: Handbook of Chinese Herbs and Formulas Los Angeles: Institute of Chinese Medicine; 1985.

74. Stuart GA: Chinese Materia Medica Shanghai: American Presbyterian Mission Press; 1911.

75. Emboden WA: Narcotic Plant London: Studio Vista; 1972.

76. Huxley A: The New RHS Dictionary of Gardening London: MacMillan Press; 1992

77. Coffey T: The History and Folklore of North American WildFlowers New York: Facts on File; 1993.

78. Coventry BO: Wild Flowers of Kashmir London: Raithby, Lawrence and Co.; 1923. 
79. Weiner MA: Earth Medicine, Earth Food New York: Ballantine Books; 1980.

80. Duke JA, Ayensu ES: Medicinal Plants of China Volume I. Michigan: Reference Publications; 1985.

81. Foster S, Duke JA: A Field Guide to Medicinal Plants of Eastern and Central North America Boston: Houghton Mifflin Company; 1990.

82. Bown D: Encyclopedia of Herbs and their Uses London: Dorling Kindersley; 1995.

83. Chopra RN, Nayar SL, Chopra IC: Glossary of Indian Medicinal Plants (Including the Supplement) New Delhi: Council of Scientific and Industrial Research; 1956.

84. Suwal PN: Medicinal Plants of Nepal Kathmandu: Department of Medicinal Plants; 1993.

85. Phillips R, Foy N: Herbs London: Pan Books Ltd.; 1990.

86. Chevallier A: The Encyclopedia of Medicinal Plants London: Dorling Kindersley; 1996.

87. Moerman D: Native American Ethnobotany Portland: Timber Press; 1998.

88. Cai JF, (Ed): The Tibetan Medicine in China Beijing: Science Press; 1995.

89. National Institute for the Control of Pharmaceutical and Biological Products, Yunnan Institute of Drug Control: The Medicinal Materials Used by the Minorities in China Beijing: People's Health Press; 1984.

90. Tian HY, Qu XY, Xiong PH: The Process of Refining Ethno-medicines in China Beijing: Ancient Book of Chinese Medicine Press; 2000.

91. Nimaciren, Wang DJ: A Summary of Tibetan Medicine - Monograph on Tibetan Medicine. China Tibetology 2007, 3: I0I-I08.

92. Guo HJ, Long CL: Biodiversity of Yunnan Kunming: Yunnan Science and Technology Press; 1998:107-120.

93. Zheng YL: Greet the spring of exploitation and utilization of ethnodrugs. Chinese Journal of Ethnomedicine and Ethnopharmacy 1997, 24:|-5.

Publish with Biomed Central and every scientist can read your work free of charge

"BioMed Central will be the most significant development for disseminating the results of biomedical research in our lifetime. "

Sir Paul Nurse, Cancer Research UK

Your research papers will be:

- available free of charge to the entire biomedical community

- peer reviewed and published immediately upon acceptance

- cited in PubMed and archived on PubMed Central

- yours - you keep the copyright

Submit your manuscript here:

http://www.biomedcentral.com/info/publishing_adv.asp
BioMedcentral 